\title{
Collaboration: the Key to Establishing Community Networks in Regional Australia
}

\author{
Wal Taylor \& Stewart Marshall \\ COIN Internet Academy, Central Queensland University, Rockhampton, Australia
}

\section{w.taylor@cqu.edu.au s.marshall@cqu.edu.au}

\begin{abstract}
Despite the promise of community involvement, cohesion and empowerment offered by local community networks $(\mathrm{CN})$ using Internet Technologies, few communities in regional Australia have been able to demonstrate sustainable and vibrant $\mathrm{CN}$ which demonstrate increased social, cultural or self-reliance capital.

The Faculty of Informatics and Communication at Central Queensland University (CQU) and a local council have established a formal alliance to establish the COIN (Community Informatics) projects to research issues around this topic. This paper presents the initial findings from this work and draws conclusions for possible comparison with other international experience.

The research focuses attention on community understanding and cohesion, local government priorities in a community with relatively low diffusion of the Internet and the competing demands in a regional university between traditional service provision in an increasingly competitive market and the needs of establishing outreach research for altruistic, industry establishment and commercial rationale.
\end{abstract}

Keywords: Community networks, community informatics, University outreach, ICT adoption

\section{Introduction}

From the huge volume of written material, there can be no doubt that the Internet has huge and unprecedented implications for society at large. Even societies seemingly untouched by it today will be affected by the changing nature of those segments which are inextricably embedding the Internet into may facets of commercial, organisational and societal life. The uneven adoption of Internet technologies across the world is great cause for concern to international collaborative bodies whose efforts are related to global inequity (UNDP,2001; DOTforce, 2001). Despite the huge potential of Internet technologies to assist communities to increase their overall well-being through community development, there are relatively few examples of sustained community networks built around Internet technologies when compared to commercial applications, even in the developed countries where the technology has been increasingly available for up to 20 years. Early work in the field has had mixed success (O'Neal, 2001) and researchers report a wide range of potential success factors and impediments (see for example, Byrne and WoodHarper, 2000; Gurstein, 2000; Kavanaugh et al, 2000; Pigg, 1999; Rosenbaum and Gregson, 1998; Schuler, 1996; Shearman, 1999). However, despite the lack of emergence of useful generic theories or

Material published as part of these proceedings, either on-line or in print, is copyrighted by Informing Science. Permission to make digital or paper copy of part or all of these works for personal or classroom use is granted without fee provided that the copies are not made or distributed for profit or commercial advantage AND that copies 1) bear this notice in full and 2) give the full citation on the first page. It is permissible to abstract these works so long as credit is given. To copy in all other cases or to republish or to post on a server or to redistribute to lists requires specific permission from the publisher at Publisher@InformingScience.org models from the current work in community informatics, there are some common elements beginning to emerge. Pre-eminent amongst these is that social network strategies and the building of social capital at the local level are key issues for the successful adoption of Internet technologies for development (Shearman, 1999; Horrigan and Wilson, 2001; Harris, 2001). Also whilst the lack of external funding 
for equipment can be a barrier to success, provision in itself is no guarantee of successful adoption in community (Harris, 2001; Byrne and Wood-Harper, 2000).

The concept of social capital (community engagement, trust and reciprocity) and its role in economic well-being in an increasingly networked developed society has been brought to prominence over recent years by Putnam (2000) and previously by a number of others including Tocqueville (1835), Bourdieu (1986). A number of researchers have examined community computer networks in relation to social capital and social ties and found that they can both increase social networks and deepen social ties (Kavanaugh et al, 1999; Horrigan, 2001). However, others make the point that the Internet in itself is not a reservoir of social capital but is merely an additional outlet for those who already have wider social networks (Uslaner, 2000).

In summary, there is an increasing interest in useful practical research into the impediments of Internet technologies for geo-community development (see for example, O’Neal, 2001; Pigg, 1999; Horrigan, 2001; Gurstein, 2000).

As a result of this, the Faculty of Informatics and Communication ('Faculty') at Central Queensland University (CQU), Australia sought to establish an action research centre to simultaneously implement and study community informatics in a provincial regional environment. Essential to this approach was the recognition that the effort must be collaborative with community in neither 'top down' nor 'bottom up' approaches but in a combination recently described as 'inside out' (Nyden, 2001) which recognises the needs for existing structures to extend their resources to address integrated community needs in equal partnerships. The theoretical basis for this Community Informatics (CI) work has been described by Romm and Taylor (2000a) and potential models further developed by Romm and Taylor (2000b and 2001). This work identified three individual macro-variables (Technology, Motivation, and Task) and three collective macro-variables (Environment, Politics and Culture) as impediments to both the rate and depth of adoption of Internet technologies for community development. Individual macro-variables apply to individual people whilst the collective ones apply to groups of people in an environmental sense. The variables interact with each other in a cumulative manner. Further analysis of the project identified Harmony, defined as the degree to which the community supports the leadership in CI projects, and Autonomy, defined as the degree to which the project is able to be controlled from within the community, as key variables in the adoption of CI projects. Analysis of current approaches to CI across Australia and internationally pointed to need for an integrated approach to address both the supply and demand sides in increasing the use of Internet products and services.

\section{The Setting}

The city of Rockhampton (on the Tropic of Capricorn in Eastern Australia) with a population of 65000 has been the traditional service and administrative centre for a large sparsely populated geography dependent upon mining, light metals processing, power generation and agriculture. As such, its rate-payer base has been expected to pay for the establishment and maintenance of cultural and social services for the region. It is the headquarters for the Central Queensland University which has 14 campuses along the eastern seaboard of Australia and the south-western Pacific rim. When compared to national and state averages, it has comparatively lower levels of formal education, income, people in the 26-55 year age bracket and home use of the Internet (25\% less) when compared to both State and National averages (ABS,2000; CQSS, 2000). It has correspondingly higher proportions of people over 55 years of age. Despite the city being both the home base for a vibrant regional University which is the third largest employer in the city and it being a substantial base for regional public service administration, home connection to the Internet was approximately 34\% which is 20 points below that of capital cities and substantially below adoption rural areas in Australia. Significantly, those over 55 years of age had home connection rates of $16 \%$ compared to $44 \%$ for the preceding cohort in the $40-55$ age bracket. 
Anecdotally, the city has relatively low levels of social capital with many groups reporting that the uptake of anything new would be delayed because of the conservative and individualistic nature of residents (Taylor, personal research). The Faculty of Informatics and Communication is the fastest growing section of the University with enrolments growing by an average $150 \%$ p.a. over the last three years.

The aims of the Action Research Centre are to :-

1. Provide computer and Internet access and training to members of community groups as a means to increase social participation.

2. Measure changes in attitude and behaviour to the use of Internet technologies for community development in individuals and the various community groups as a result of the project.

3. Assist community groups develop an integrated approach to the use of Internet technologies for community development.

The project employs Participative Action Research (PAR) methodology in a manner which allows the separation of the project's operational outcomes and the analysis of the processes involved, after the dual approach subsequently proposed for information systems research by McKay and Marshall (2001).

The project commenced in mid 1999 and the COIN Internet Academy as a joint effort between the Faculty and the Rockhampton City Council ('Council') was opened in mid 2001 with two project managers, administration support, two post-graduate researchers, (all on short term funding) a ten-seat training facility and a nine-seat telecentre. A Steering Committee comprising three representatives each from the Faculty and the Council had been in operation for 12 months and established a Memorandum of Understanding between the Faculty and the Council. This approach reflects the key finding from a recent workshop examining the digital divide in that useful approaches to addressing the digital divide require 'organisations in a strategic compact set off a development dynamic'.(Cohen, 2001) The appointments of a senior research officer on a two-year contract and an interim part-time manager were subsequently approved by the Faculty and the COIN steering committee. In the first three months of operation the COIN Internet Academy had conducted more than 3000 hours of training in structured sessions with 14 community groups.

Initial survey work conducted at the commencement and after six weeks exposure to training with the commencing group of seniors (targeted as a result of their extremely low adoption rates) found that there was:-

1. $25 \%$ reduction in fear

2. $33 \%$ reduction in perceptions of difficulty of use

3. $36 \%$ increase in defining useful home based applications

4. $\quad 25 \%$ reduction in cost as an impediment

5. $40 \%$ reduction in individual skills as an impediment, and

6. An almost total rejection of the proposition that the Internet was having bad societal effects from an original position of ambivalence.

The COIN Internet Academy now has 37 community groups registered as members for a wide range of programs including 'train the trainer' programs to provide for wider diffusion.

\section{The Questions and the Lessons}

Obviously the main question centres around what were the impediments to establishment and legitimisation when even a rudimentary analysis identified a need that key stakeholders recognised. In other words, why did it take two years to establish the project when it involved two significant organisations (a Univer- 
sity and a local government) with obvious needs to address the issue of low demand for Internet products and services in their constituency? The attendant question relates to sustainability. As well as this, there is value in examining the methodology retrospectively with a view to planning subsequent action. All of these issues fit into reflection, evaluation and planning of a participative action research approach.

In examining issues that affected the establishment, interviews were conducted with senior organisational staff, elected members in the stakeholder organisations, focus groups representing 12 socio-economic groups and community members using the COIN Internet Academy.

\section{Stage I}

The initial attempts to pilot a CI approach were confined to a suburb of the target area and was heavily based on the involvement of schools as both adopters and influencers in the local community. The major objectives were to have class, teacher, parent and the Parent and Teacher Association email lists established to facilitate greater involvement through asynchronous electronic communication between all levels in the school community. This approach to establishing active email lists in the school stakeholder groups failed because the school administrators and teachers did not see a value of involving parents, teachers and students in an open dialogue using Internet technologies. This was despite the fact that the project was able to provide full assistance in establishing the email lists. The schools were mostly part of a state based and hence centralised educational system which did not have operational flexibility to either take the initiatives on or reduce other requirements to provide staff time. Subsequent evaluation determined that project leader credibility and a history of the University starting but not finishing community based projects and 'taking but not giving' were also significant issues.

\section{Stage II}

As a result of reflection and analysis, the second cycle of the Action Research approach involved aligning the project more at organisational levels in the University (the Faculty level) and with the Council (CEO and Mayor). Joint funding submissions to Government agencies (Federal and State) and business were developed by the Faculty and subsequently funded. The Faculty provided substantial cash contributions to match these funds and to equip the COIN Internet Academy in the centre of the city with computers, staff support and accommodation for four Council employees at very reduced rates. To further facilitate an integrative approach, the Faculty agreed that the externally funded staff positions should become a part of the Council staff compliment and report operationally through the Council. This was done with the aim of increasing the understanding of a CI within Council staff and elected representatives.

This cycle produced a number of learnings which can be deduced from the summary provided in Table 1. At the outset it was recognised that no one agency (public or private) had the responsibility for increasing the use of CI for community development. More particularly, the traditional structure of government agencies including local government and educational systems viewed Internet technologies only as an additional tool for existing service provision and this mitigated against the concept of CI for community development. It does this in a number of related ways which are dealt with in the following paragraphs.

With increased fiscal accountability based on output budgeting, core issues related to established norms become entrenched within the operational framework of many government agencies, 'not for profits' dependent upon external funding and corporate organisations. As a result, this limits the potential benefits of Internet technologies as existing systems try to fit the technology to traditional practise rather use the technology to develop new approaches. 
Table 1: Perceived impediments to the establishment of a collaborative CI Action Research Centre in Rockhampton by Council and University stakeholders

\begin{tabular}{|c|c|c|}
\hline Macro-variable & Rockhampton City Council & Faculty \\
\hline $\begin{array}{l}\text { Technology } \\
\text { (friendliness) }\end{array}$ & $\begin{array}{l}\text { - Organisation, community and } \\
\text { individuals not comfortable with } \\
\text { Internet technology }\end{array}$ & $\begin{array}{l}\text { - Not comfortable that useful tech- } \\
\text { nology for CI is developed yet }\end{array}$ \\
\hline $\begin{array}{l}\text { Motivation } \\
\text { (to adopt) }\end{array}$ & $\begin{array}{l}\text { - Focus on business - economic } \\
\text { rationalist approaches } \\
\text { - Fear of looking silly when deal- } \\
\text { ing with CQU } \\
\text { - Fear of being stuck with project } \\
\text { - after project funding ceases } \\
\text { - Risk averse to new projects }\end{array}$ & 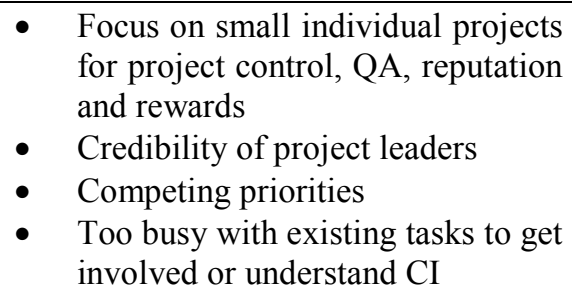 \\
\hline $\begin{array}{l}\text { Task } \\
\text { (appropriateness of } \\
\text { technology) }\end{array}$ & $\begin{array}{ll}\text { - } & \text { It won't replace face-to-face } \\
\text { - } & \text { Internet not seen as important } \\
\text { - } & \text { 'Hoax' \& 'trust' aspects } \\
\text { - } & \text { More a capital city activity }\end{array}$ & $\begin{array}{l}\text { - } \quad \text { CI not core business } \\
\text { - Models and theory not yet devel- } \\
\text { oped } \\
\text { - } \begin{array}{l}\text { Risk and don't have resources to } \\
\text { compete with larger bodies }\end{array} \\
\end{array}$ \\
\hline $\begin{array}{l}\text { Organisational En- } \\
\text { vironment for } \\
\text { Community Prac- } \\
\text { tice }\end{array}$ & $\begin{array}{l}\text { - Conservative staff and commu- } \\
\text { nity does not allow for new con- } \\
\text { cepts in the traditional planning } \\
\text { processes } \\
\text { High staff turnover - lack of } \\
\text { continuity for innovative pro- } \\
\text { jects } \\
\text { New financial accountability } \\
\text { measures eg output budgeting } \\
\text { reduces flexibility } \\
\text { Low understanding of commu- } \\
\text { nity practice across elected and } \\
\text { employed RCC }\end{array}$ & $\begin{array}{l}\text { - Administrative and financial sys- } \\
\text { tems inadequate to handle collabo- } \\
\text { rative community practice projects } \\
\text { - Limited incentives or rewards for } \\
\text { staff involvement. } \\
\text { - IT education is growth area and } \\
\text { inadequate resources stretch ca- } \\
\text { pacity and QA for traditional jobs; } \\
\text { thus reduces capacity for new ac- } \\
\text { tivities } \\
\text { Increased measures in financial } \\
\text { accountability limit funding initia- } \\
\text { tives in community }\end{array}$ \\
\hline $\begin{array}{l}\text { Culture } \\
\text { (organisational and } \\
\text { community culture) }\end{array}$ & $\begin{array}{l}\text { - } \text { CQU and RCC not good at part- } \\
\text { nerships } \\
\text { - } \\
\text { Politically acceptable to deride } \\
\text { education } \\
\text { - } \quad \text { Community doesn't trust Uni } \\
\text { Risk averse - incrementalism } \\
\text { pays, innovation costs. } \\
\text { - Cost-benefit analysis, focuses } \\
\text { effort on traditional activities }\end{array}$ & $\begin{array}{l}\text { - Focus on supply side of teaching } \\
\text { - Focus on individual rewards vs } \\
\text { collaborative effort } \\
\text { - Poor organisational history in } \\
\text { community-based research; lack } \\
\text { of acceptance and skill }\end{array}$ \\
\hline $\begin{array}{l}\text { Politics } \\
\text { (harmony, shared } \\
\text { values, power rela- } \\
\text { tionships) }\end{array}$ & 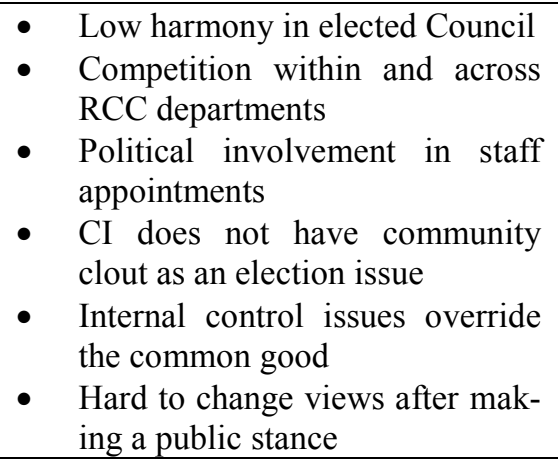 & $\begin{array}{l}\text { - Tall poppy syndrome } \\
\text { - Competitive academic environ- } \\
\text { ment } \\
\text { - Status and conditional self-esteem } \\
- \text { particularly in administration } \\
\text { and finance } \\
\text { - Threats of changes in internal } \\
\text { power relationships in administra- } \\
\text { tion and finance areas } \\
\text { - Perceptions of an internal class } \\
\text { hierarchy }\end{array}$ \\
\hline
\end{tabular}

Source: Taylor 2002, unpublished thesis 


\section{A Possible Explanation}

Critical Theory has contended since the 1930's that the values associated with technicism and instrumental rationality have increasingly and destructively dominated public service delivery in modernity (Agger, 1991; Held, 1980). From this perspective there then develops an overly goal orientated approach in both organisations and individuals (Gorry and Scott-Morton, 1971; Dryzek, 1990). This goal-oriented approach can create a "tunnel vision" that may blind operants and managers to alternative approaches (Williams and Duczynski, 2000). Foremost in these goal seeking approaches, is a unitary vision of an organisation where society is perceived as an integrated whole with the interests of the individual, the organisation and society as synonymous. (Falconer, Castleman, Mackay, and Altmann, 2000).

Fundamental to this is the concept of calculative rationality (Dreyfus, 1998; Falconer et al 2000) where decisions are made on undivided organisational interests, which may contravene widely held societal values and interests (Weber, 1930). Hence, the process of rationalisation with in public and private agencies has serious negative consequences for society at large (Salaman, 1981).

\section{Moving Forward}

Processes for changing this are not easy. One process available in Australian local government and state government arena, is community consultation in developing strategic plans or targeted outputs for delivery within the three-year election cycle. However, as pointed out above, in conservative environments such as exist in Rockhampton, community consultation does not yield strong support for new concepts. Even if it did, the new concepts would then have to withstand the 'calculative rationality' of employees and elected representatives. In these environments, then change has to be introduced by 'champions' (individuals or organisations) who then have to face the hurdles of legitimacy, organisational embeddedness, sustainable energy, resource allocation, and 'turf-protection' from existing stakeholders using current politically-acceptable terminology to describe traditional behaviour. Much of the eventual success in establishing the COIN Internet Academy was the result of collaborative championing by the Faculty and the Council

Significantly, the elected decision-making process is very susceptible to elector concerns. CI is a demand driven approach and hence its ability to become an institutionalised activity in local governance can be affected by community pressure across a wide socio-economic spectrum. The initial changes in attitude and subsequent behaviour by members of community groups using the COIN Internet Academy give promise for increasing community support for CI initiatives in the Rockhampton community.

This brings the concepts of social networks and social capital back into focus. As pointed out in the introduction, these constructs and their antecedents (trust, reciprocity, community aspirations, community capacity to act, participation, relationships, personalities, willingness to learn etc) are increasingly being seen as the crucial elements in a community informatics approach. The work to date in establishing the COIN Internet Academy would support the importance of these issues in speeding up establishment, but more importantly in achieving sustainability.

\section{Conclusions}

This paper has outlined the principal impediments to the establishment of an action research centre to establish a community informatics approach in a regional urban city where the use of Internet technology is relatively low. It has assessed this against a framework proposed by Romm and Taylor. It concludes that the interaction between entrenched public agency service provision processes (as a component of the environment), politics and culture when coupled with poor understanding of technology-fit reduces motivation for decision makers to embed support for the use of Internet technologies for community development in existing processes or to establish new ones. A possible response lies in focussing on changing the attitude and behaviour of community members who are currently disadvantaged by poor understanding 
and poor access by working at their level to build confidence and self- esteem in the use of Internet technologies. This requires collaborative championing by 'influencers' in lead agencies with wide social responsibilities.

The constructs of 'individual liberalism' and 'calculative rationality' can not only disadvantage and disempower individuals and groups who are not in organisational frameworks which provide access and skills acquisition for use of Internet technologies, but also prevent those that are in these organisational frameworks from seeing the benefits from using Internet technologies for community development.

As a result, places with higher levels of social capital and better social networks stand to be able to make better and faster use of basic Internet technologies for community development and mobilisation than those with lower levels, even though these communities may have substantial advantages in Internet access, disposable income and agency programs.

\section{Future Research}

The findings of this research provide the basis for developing new research directions aimed at determining factors affecting the use of ICT for community practice. Fundamental to this, is the examination of the effects of ICT in the establishment and maintenance of weak network ties in a community practice construct. This research found that in this environment there was not a large demand from the community for the use of ICT form community practice. Other research associated with this study has also identified relatively low social engagement in this particular community. As a successful community informatics approach appears dependent upon a level of social engagement, it would be useful to examine the relationship between social engagement and the adoption of a community informatics approach for local community benefit. It would also be useful to determine the role of ICT in defining factors affecting organisational capacity to meet social engagement goals articulated in corporate strategies. Further, this study points to the need to examine factors affecting the use of ICT for community consultation and participation in the public agency-governance-community nexus.

\section{References}

ABS (2000). Australian Bureau of Statistics Annual Economic Activity Survey. Sections 31, 32, 41 \& 42 http://www.abs.gov.au/ausstats/abs\%40.nsf/7884593a92027766ca2568b5007b8617!OpenView

Agger, B. (1991). A Critical Theory of Public Life: Knowledge, Discourse and Politics in an Age of Decline. London, Palmer Press.

Bourdieu, P. (1986) The forms of Capital in Handbook of Theory and Research for the Sociology of Education. Ed John Richardson. Greenwood Press. New York

Byrne, B.K. and Wood-Harper, T (2000). Community Regeneration and ICT: Is this the answer ?. In Proceedings Australian Conference for Information Systems (ACIS) Brisbane 6-8 December. http://www.fit.qut.edu.au/ACIS2000/full_papers.html.

Cohen, N (2001). Director Digital Dividends Project, World Resources Institute, in summing up the 'Getting beyond the Digital Divide after the Genoa G8 Summit' workshop, Zurich, 12 October 2001. http://www.hsw.fhso.ch/ruddy/Workshop_2.htm

CQSS(2000) Central Queensland Social Survey. Population Research Laboratory, Central Queensland University, Rockhampton, QLD.

Digital Opportunities Task Force (2001). Digital Opportunities for All: Meeting the Challenge. http://www.bellanet.org/dotforce/docs/DOT_Force_Report_V_5.0f.doc?ois=y;template=blank.htm.

Dreyfus, Hubert, (2000) On the Internet: Thinking in Action, London: Routledge.

Dryzek, J.S. Green Reason: Communicative Action for the biosphere, Environmental Ethics. 12(3),195-211. 


\section{Collaboration}

Falconer, D.J., Castleman, T., Mackay, D.R. and Altmann, G. (2001) Critical Approaches to Information Systems Planning: Refining the Research Agenda, Proceedings of the 33rd Hawaii International Conference on System Sciences, Los Alamitos ,CA, IEEE Computer Society.

Gorry, G.A. and Scott Morton, M.S. (1971) A Framework for Management of Information Systems, Sloan Management Review, 13(1) 55-70.

Gurstein, M. (2000) Community Informatics: Enabling communities with communications technologies. IDEA Group Publishing. Hershy, USA, ISBN 1878289691 pp 1-20.

Harris, R. (2001). Research Partnerships to Support Rural Communities in Malaysia With Information and Communication Technologies, in Managing IT/Community Partnerships in the 21st Century, edited by Jonathan Lazar, Idea Group Publishing. Forthcoming.

Held, D. (1980) Introduction to Critical Theory, Polity Press, Cambridge: Polity Press.

Horigan. J.B. (2001). Online Communities: The Internet's role in fostering e-groups and deepening people's ties in their local community. Internet Research 2.0: INTERconnections, the second conference of the Association of Internet Researchers (AoIR), October 10-14, 2001, The University of Minnesota, Minneapolis, Minnesota.

Horrigan, J.B. and Wilson, R.H. (2001). Telecommunications Technologies and Urban Development: Strategies in US cities. Pew Internet and American Life Project. http://www.pewinternet.org/papers/index.asp

Kavanaugh, A.L., Cohill, A.M. and Patterson, S. (2000). Use and Impact of Community Networking in Blacksburg.

McKay, J. and Marshall, P. (2001). The dual Imperatives of action research. Information Technology and People. Vol 14 (1). http://emerald-library.com/brev/16114ac1.htm.

Nyden, P. (2001). University and Community Engagement: The view from Chicago and the US. Keynote address presented at the Inside Out: Higher Education and Community Engagement Conference. 16-19 July 2001. Community Service and Research Centre, University of Queensland, Ipswich, Australia.

O’Neal, D. (2001). Merging theory with practice: Toward an evaluation framework for community informatics, paper presented at Internet Research 2.0: INTERconnections, the second conference of the Association of Internet Researchers (AoIR), October 10-14, 2001, The University of Minnesota, Minneapolis, Minnesota.

Pigg, K. (1999). A Demand Side Policy Needed to Extend the Information Superhighway. Community Technology Review. Summer-Fall 1999. pp 45-46. Community Technology Centres Network, Newton, MA.

Putnam (2000). Bowling Alone: The Collapse and Revival of American Community. Simon and Schuster. New York

Romm, C. and Taylor, W. (2001) The Role of Local Government in Community Informatics Success Prospects: The Autonomy Harmony Model. Proceedings of the 34Th Hawaii International Conference on System Sciences, Los Alamitos CA, IEEE Computer Society,2001 (CD ROM)

Romm, C. and Taylor, W. (2000a). Community Informatics: the Next Frontier. In Challenges of Information Technology Management in the $21^{\text {st }}$ Century. Proc of IRMA. conference. Ed. M.Khosrow-pour. Idea Group Publishing, Hershy PA. 21-24 May ISBN 1878289845 pp 1167-1169.

Romm, C. and Taylor, W.. (2000b). Thinking Strategically About Community Informatics: The Action, Reaction, Integration (ARI) Model. In Electronic Commerce and Web Based Systems. Proc. Pacific Asia Conference on Information Systems.(PACIS) Eds. K.Tam and P.Chan. University of Hong Kong 1-3 June . pp 588-599.(CD ROM).

Rosenbaum, H and Gregson, K. (1998). A study of State-Funded Community Networks in Indiana: Final Report: Submitted to the Indiana Department of Education, Center for School Improvement and Performance.

Salaman, G. (1981) Class and the Corporation. London: Fontana.

Shearman, C. (1999). Local Connections: Making the Net Work for Neighbourhood Renewal. Communities Online. London. www.communities.org.uk

Schuler, D. (1996) New Community Networks: Wired for Change. Addison-Wesley, Reading. MA.

Taylor, W. (2002). Factors Affecting the Adoption of Internet Technologies for Community Practice in a Regional Area. Unpublished PhD thesis. Faculty of Informatics and Communication, Central Queensland University.

Tocqueville, A (1945) Democracy in America. Vintage Books, New York. Originally published in 1835.

United Nations Development Program. (2001). The Human Development Report.

http://www.undp.org/dpa/publications/index.html. 
Weber, M. (1930). The theory of Social and Economic Organization, New York: Free Press.

Williams, M.C. and Duczynski, G.(2000) Moral Poverty of Computing Higher Education, in Sudweeks F. and Ess, C. (eds), Cultural Attitudes Toward Technology and Communication, School of Information Technology, Murdoch University, Murdoch, WA, Australia

\section{Biographies}

Professor Stewart Marshall is the founding Dean of the Faculty of Informatics and Communication at Central Queensland University. He has a wide experience in IT educational processes in academic, community and policy settings in four countries. His Faculty provides undergraduate, graduate and postgraduate teaching and research programs across 14 campuses in eastern Australia and the south western Pacific. Professor Marshall has particular interests in the use of ICT for inclusive educational programs, both in face-to-face and distance education, the changing face of tertiary education in relation to community engagement and community empowerment, particularly in disadvantaged and indigenous communities.

Wal Taylor coordinates the operations of the COIN Internet Academy at Rockhampton, Australia. This is a collaborative effort between the Faculty of Informatics and Communication at Central Queensland University and the Rockhampton City Council. The COIN Academy was founded as an action research centre to examine the use of ICT for community practice and as such its operational scope fits with in the emerging field of Community Informatics. Wal has had more than 30 years experience in program service delivery for and the analysis of regional and rural community consultation, participation and policy development processes. 